SUPPLEMENTARY MATERIAL

\title{
A new acylated flavonol from the aerial parts of Asteriscus maritimus (L.) Less (Asteraceae)
}

\author{
Marwa I. Ezzat ${ }^{\mathrm{a}^{*}}$, Shahira M. Ezzat ${ }^{\mathrm{a}}$, Ahlam M. El Fishawy ${ }^{\mathrm{a}}$, Kadriya S. El Deeb ${ }^{\mathrm{a}}$, and \\ Sayed A. El Toumy ${ }^{\mathrm{b}}$. \\ a Pharmacognosy Department, Faculty of Pharmacy, Cairo University, Kasr-el-Aini \\ street, 11562 Cairo, Egypt. \\ ${ }^{\mathrm{b}}$ Chemistry of Tannins Department, National Research Centre, Tahrir street, Dokki, \\ Cairo, Egypt. \\ *Corresponding author at: Department of Pharmacognosy, Faculty of Pharmacy, Cairo \\ University, Kasr-el-Aini street, 11562 Cairo, Egypt.. Tel.: +201009395028. E-mail \\ address: drmarwanada@yahoo.com (Marwa I. Ezzat).
}

\begin{abstract}
Phytochemical investigation of the flowering aerial parts of Asteriscus maritimus (L.) Less (Asteraceae) led to the isolation of a new compound; patuletin 7- $O-\beta$-D-[(2 ' ' S ) 6 "(3"'-hydroxy-2"'-methyl-propanoyl)] glucopyranoside, together with five known metabolites; $\beta$-sitosterol 2, chlorogenic acid 3, $P$-hydroxy -methylbenzoate $\mathbf{4}$, luteolin $\mathbf{5}$ and protocatechuic acid $\mathbf{6}$. The structures of the isolated compounds were determined by comprehensive analyses of its 1D and 2D NMR, HRMS and comparison with previously known analogues. The ethanolic extract of the flowering aerial parts of A. maritimus was found to be safe $\left(\mathrm{LD}_{50}=4.6 \mathrm{mg} / \mathrm{kg}\right)$ and possess significant anti-oxidant and antiinflammatory activities and this was in accordance with its high phenolic content (107.36 $\pm 0.051 \mathrm{mg} \mathrm{GAE} / \mathrm{g}$ extract).
\end{abstract}

\section{Keywords:}

Asteriscus maritimus, acylated flavonol, anti-oxidant, anti-inflammatory. 


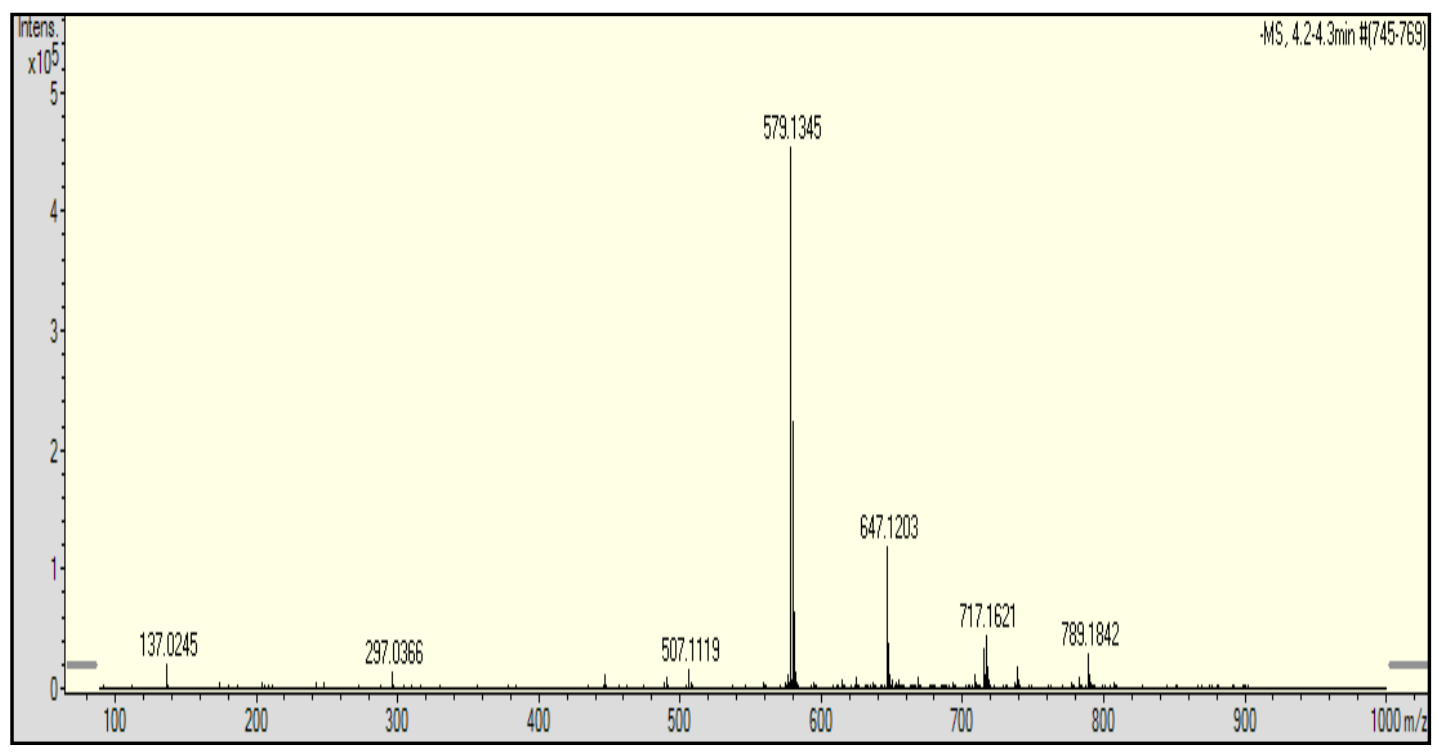

Fig.S1. HRESI-Ms

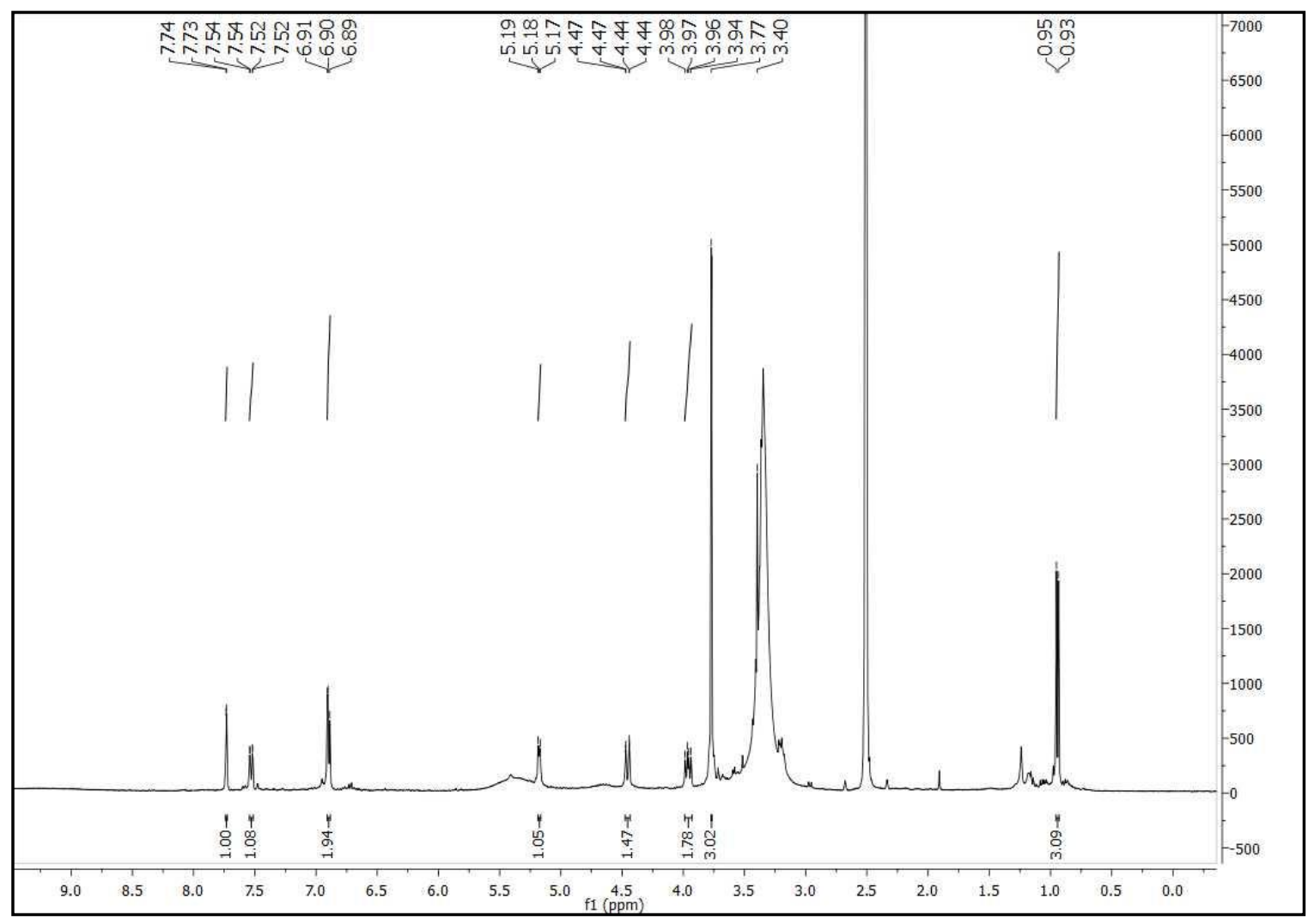

Fig. S2. ${ }^{1} \mathrm{H}$ NMR 


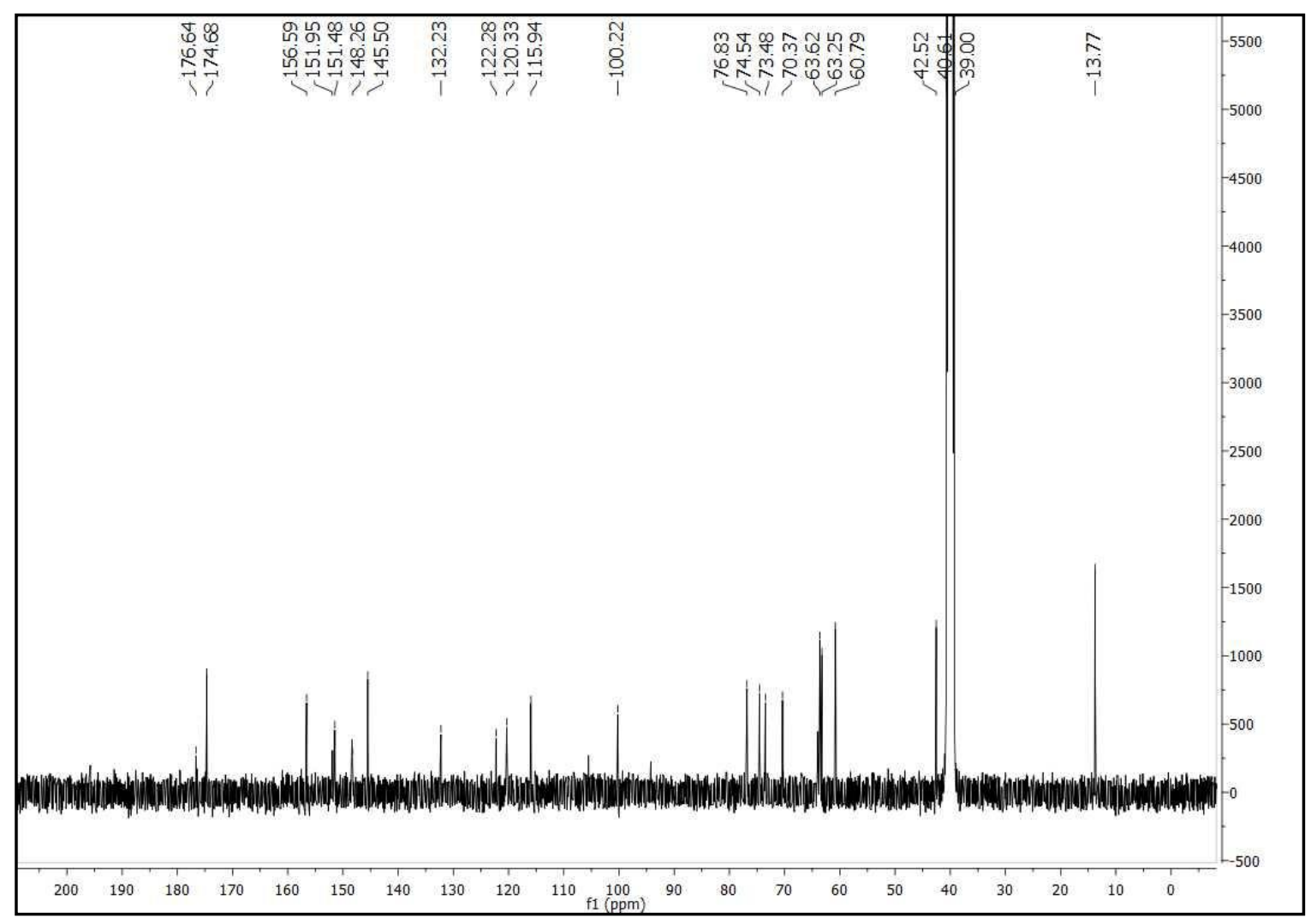

Fig. S3. ${ }^{13} \mathrm{C}$ NMR

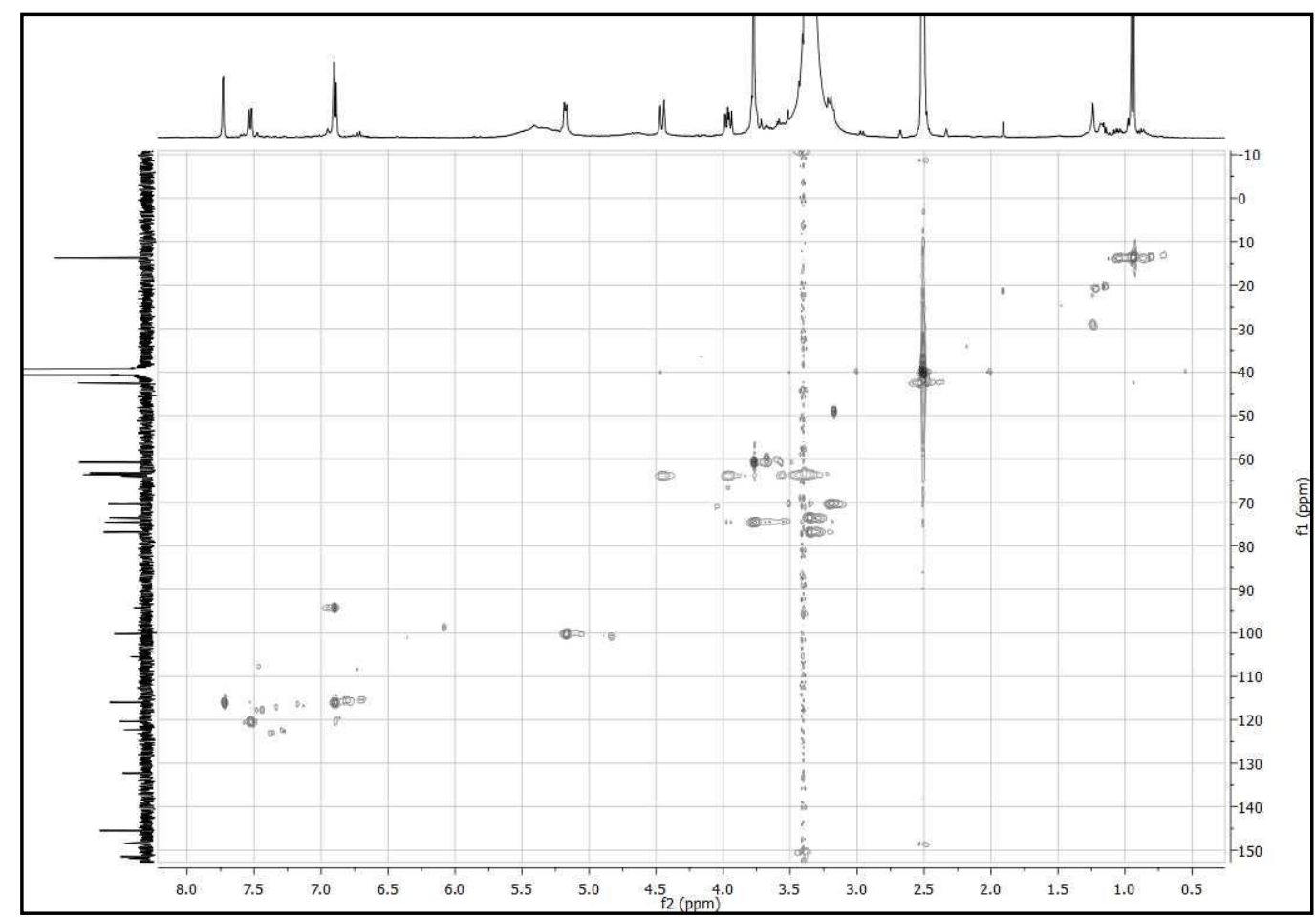

Fig.S4. HMQC 


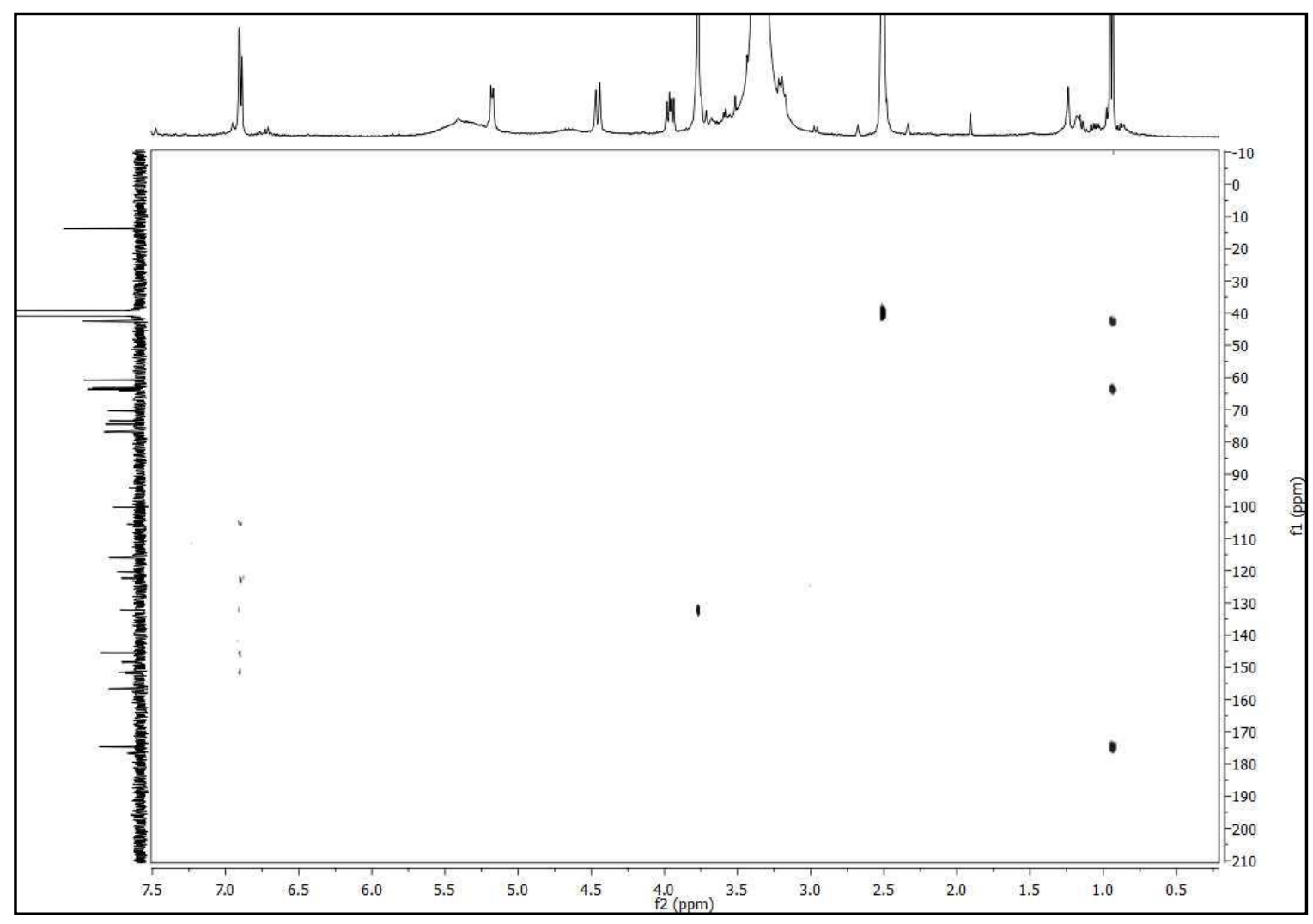

Fig.S5. HMBC 


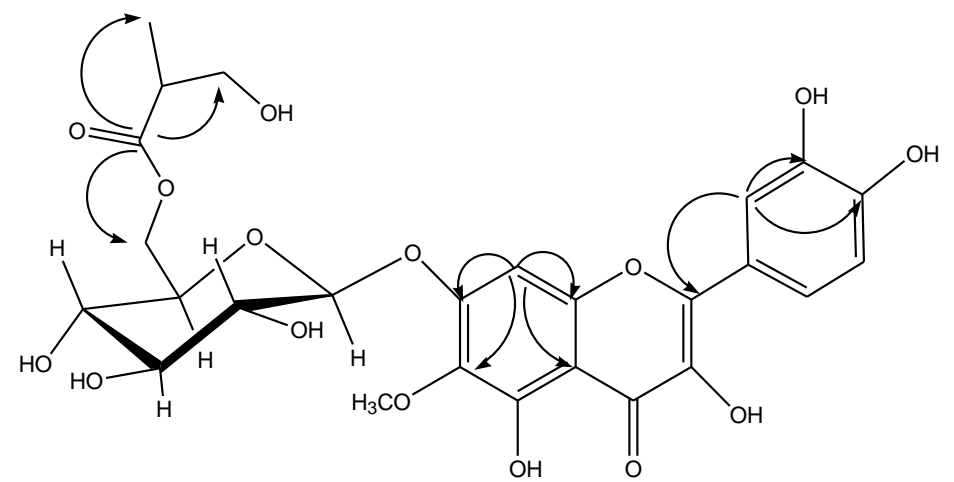

Fig. S6. HMBC correlations H- C of compound 1. 